\title{
Capacitação e desenvolvimento docente - aspectos gerais
}

\section{Teacher training and faculty development - general aspects}

\author{
Maria José López¹, Luiz E. A. Troncon²
}

\begin{abstract}
RESUMO
A atuação docente no ensino superior na área da saúde requer que o professor, além da expertise na sua disciplina, tenha também preparo na área educacional. Este preparo fundamental pode ser obtido em programas específicos de capacitação e deve ser mantido e aperfeiçoado em atividades de desenvolvimento docente. Os programas de capacitação e desenvolvimento docente são o objeto deste texto, de caráter introdutório, que trata dos atributos necessários ao bom professor, no desempenho dos vários papéis e funções que dele se espera, e das características de forma e conteúdo desejáveis nos programas de capacitação e desenvolvimento docente. Aborda-se, ainda, como estas atividades podem ser avaliadas visando o seu aperfeiçoamento constante e as dificuldades e desafios que habitualmente enfrentam. Apresentam-se, também, breves descrições de atividades de capacitação e desenvolvimento docente realizadas na Faculdad de Ciencias Medicas da Universidad Nacional de Cuyo, em Mendoza, Argentina, e na Faculdade de Medicina de Ribeirão Preto da Universidade de São Paulo, em Ribeirão Preto, Estado de São Paulo, Brasil.
\end{abstract}

Palavras-chave: Professor/Programas de Treinamento. Docentes/Capacitação. Educação Superior. Educação/Profissões de Saúde. Educação Médica.

\begin{abstract}
Teaching in higher education in the health professions requires not only discipline expertise but also that the teacher is acquainted with contents and techniques in the educational field. This can be obtained in specific teacher training programs and should be maintained and improved in faculty development activities. This paper deals with introductory aspects of teacher training programs and faculty development activities and addresses the attributes that a good teacher should have when performing in his/her various roles. The contents and formats desirable in teacher training programs and faculty development activities are also presented. This paper also briefly discusses how these activities can be evaluated aiming at their continuous improvement and the difficulties and challenges they routinely face. This paper also presents brief descriptions of teacher training and faculty development initiatives carried out in two South American institutions, in Mendoza, Argentina, and in Ribeirao Preto, State of Sao Paulo, Brazil.
\end{abstract}

Keywords: Faculty/Training Programs. Faculty/Training. Education, Higher. Education, Health Professions. Education, Medical.

1. Docente da área de Educação, Diretora do Centro de Apoio Pedagógico, Facultad de Ciencias Médicas, Universidad Nacional de Cuyo, Mendoza, Argentina;

2. Docente. Departamento de Clínica Médica, Faculdade de Medicina de Ribeirão Preto, Universidade de São Paulo, Brasil.
Correspondência:

Prof.Dr. Luiz Ernesto de Almeida Troncon Divisão de Gastroenterologia do Departamento de Clínica Médica Hospital das Clínicas da FMRP CEP: 14048-900 - Ribeirão Preto/SP ledatron@fmrp.usp.br 


\section{Introdução}

Embora possa parecer óbvio que um docente do ensino superior deva ter preparo específico para exercer as funções de ensino, existem enormes diferenças entre os vários pontos de vista sobre a natureza deste preparo e como ele deve ser feito. Um ponto em comum entre as diferentes opiniões sobre o tema é que o professor deve ter domínio do conteúdo que vai ensinar. Porém, torna-se cada vez mais claro para todos que trabalham no ensino que o docente deve ter também algum preparo na área educacional, sobretudo nos campos da pedagogia e da didática, para poder ensinar melhor.

Este texto trata da aquisição deste preparo e da sua manutenção e aperfeiçoamento. Neste sentido, será utilizado o conceito de "capacitação" para designar a introdução ou o preparo inicial do futuro professor em temas educacionais e o conceito de "desenvolvimento docente" para a manutenção e o aprimoramento deste preparo, com a aquisição de novas habilidades e competências no campo educacional, pelo professor já em exercício da sua atividade docente.

Trata-se de um texto de caráter introdutório, baseado em grande parte na experiência acumulada dos autores, que atuam em diferentes instituições, porém colaborando entre si. Suas partes principais são: a descrição dos atributos necessários ao bom professor, as características de forma e conteúdo desejáveis nos programas de capacitação e desenvolvimento docente e como estas atividades podem ser avaliadas visando o seu aperfeiçoamento constante. Serão também descritas brevemente algumas experiências na condução destes programas e serão apresentados os principais desafios e dificuldades para a execução destas atividades.

\section{Atributos necessários ao bom professor}

Não há dúvidas que o professor deve ter o domínio dos conteúdos que ensina, mas cabe discussão sobre a abrangência e a profundidade necessárias. No ensino de graduação, a abrangência tem maior importância que a profundidade; nos vários tipos e diferentes estágios do ensino pós-graduado, a profundidade adquire maior pertinência.

Estas considerações se aplicam bem quando se considera o professor no seu papel de transmissor do conhecimento, mas comportam visão diferente quando o docente assume o papel de facilitador do apren- dizado dos estudantes, situação que se coloca, cada vez mais, como mais importante e mais requerida no ensino superior nas profissões da saúde. Muitos educadores consideram que este papel de facilitador do aprendizado é desempenhado com mais eficiência quando o docente não tem o domínio completo do conteúdo que os estudantes devem aprender. À época da consolidação da introdução pioneira do método de "aprendizado baseado em problemas" na Faculdade de Ciências da Saúde da Universidade McMaster, em Hamilton, Ontário, Canadá, no decurso de acaloradas discussões sobre este tema, chegou a prevalecer o ponto de vista que o "tutor" mais eficiente seria aquele que não tivesse qualquer domínio dos conteúdos relacionados ao problema estudado, mas que tivesse bem desenvolvidas as habilidades de manter o grupo interessado no problema e ativo na busca de conhecimentos que pudessem levar à sua solução (comunicação pessoal do Professor Howard Barrows a um dos autores, em 1995). Nos dias de hoje, na maioria das escolas que usam exclusivamente este método, prevalece a opinião que o tutor deve ter grau mínimo de domínio deste conteúdo, que lhe faça sentir-se confortável e interessado durante as discussões do problema pelos estudantes, bem como que lhe permita detectar e corrigir distorções de conceitos aprendidos pelos estudantes.

No entanto, no campo do ensino profissional ou clínico, propriamente dito, o domínio das habilidades clínicas e a competência profissional geral, são extremamente importantes e imprescindíveis dentro do elenco de atributos do professor, junto com elementos da sua personalidade e com sua proficiência para ensinar. $^{1}$

Além dos papeis de transmissor de conhecimentos e de facilitador do aprendizado, o professor da escola contemporânea do ensino superior nas profissões da saúde pode ter que desempenhar uma variedade de outras funções ${ }^{2}$, como se assinala no Quadro 1. Estes papéis se enquadram em quatro dimensões a) ensino; b) contato com estudantes c); auxílio à distância ao estudante; d) atuação clínica ou profissional. Cada um dos diferentes papéis, nestas dimensões, demanda a aquisição de habilidades e competências específicas, algumas de cunho profissional, outras de cunho educacional, do que vai resultar diferentes expertises docentes.

Nas profissões da saúde, é inegável a importância do papel de modelo de comportamento ("role model"), que exige atributos de competência profissional clínica e também de ensino, considerando as 
Quadro 1. Diferentes papéis esperados no professor nas modernas escolas das profissões da saúde. ${ }^{2}$

\begin{tabular}{ll}
\hline Funções & Papéis \\
\hline Assessor & - Assessor dos estudantes \\
& - Avaliador do currículo \\
Facilitador & - Facilitador do aprendizado dos estudantes \\
& - Mentor de indivíduos ou grupos \\
Planejador & Planejador de currículos \\
& - Organizador de cursos \\
Provedor de recursos & Produtor de material didático \\
& - Produtor de guias e roteiros de estudo \\
Provedor de informações & - Provedor de ensino clínico \\
& \\
Modelo de comportamento & - Como ambiente de ensino \\
&
\end{tabular}

evidências da sua forte influência na formação e no tipo de atuação futura do estudante. ${ }^{1,3}$

Alguns estudos indicam que as qualidades mais importantes nos modelos seriam: competência clínica, tratamento empático e solidário aos pacientes, entusiasmo pela profissão, integridade, atitude positiva frente às dificuldades sentidas por colegas de profissão mais jovens, bem como, também, habilidade para ensinar. ${ }^{3}$ Comparado com outros colegas, que não foram identificados por estudantes como bons modelos de comportamento profissional, os "role models" investem mais tempo no ensino e na atividade clínica e explicitam com maior frequência a importância da relação médico-paciente e dos aspectos psicossociais da profissão.

A aquisição destes atributos, que, de modo geral, ligam-se às figuras do profissional, do professor e da própria pessoa que as corporifica, depende de sólida formação profissional e de contínuo desenvolvimento pessoal, bem como de específica capacitação para a docência.

\section{Elementos desejáveis nos progra- mas de capacitação e desenvolvi- mento docente}

O objetivo deste segmento é dar uma visão ampla das características mais frequentes dos progra- mas e atividades de formação docente descritos na literatura especializada, junto com apresentação dos atributos que se consideram desejáveis. Apresentamse, a seguir, descrição dos conteúdos mais frequentes e dos formatos mais utilizados, que são, também resumidos nos Quadros 2 e 3.

Com relação aos conteúdos, as atividades de capacitação e desenvolvimento docente geralmente incluem um ou mais dos seguintes eixos temáticos:

- Tópicos instrucionais: trata-se do grupo de conteúdos com maior presença nas atividades de formação inicial e continua do docente. Compreende o desenvolvimento de habilidades gerais de ensino, devolutiva (feedback) e avaliação e pode, também, incluir princípios teóricos do ensino e aprendizagem. Por exemplo, é frequente a focalização em habilidades para o ensino clinico, palestras e apresentações efetivas, facilitação em grupos pequenos, avaliação de habilidades clinicas, supervisão efetiva e feedback, desenvolvimento de habilidades de raciocínio clinico, entre outras. ${ }^{4,5,6}$

- Aspectos relativos à instituição de ensino: é difícil considerar os componentes dos processos de ensino e aprendizado como sendo isolados, sendo importante identificar suas relações com outras instâncias. Cada docente individual é parte de uma organização educacional maior e se vê afetado por ela de várias formas. $\mathrm{O}$ docente precisa ter oportu- 
Quadro 2. Conteúdos frequentemente descritos em programas de capacitação e desenvolvimento docente ${ }^{6,10}$.

Conteúdos Características

Tópicos instrucionais

Discussões sobre princípios teóricos do ensino e aprendizagem, habilidades gerais de ensino, métodos de ensino (aulas, palestras, facilitação em grupos pequenos, supervisão do aprendizado clínico), técnicas de feedback efetivo, avaliação da aprendizagem.

Aspectos institucionais

Desenvolvimento profissional acadêmico

Abordagem de outras áreas específicas do ensino
Apresentações e discussões sobre cultura institucional, estrutura organizativa e normativa da instituição, currículos e modelos pedagógicos adotados, estilos de liderança prevalentes.

Discussões sobre habilidades acadêmicas profissionais, orientação na condução das carreiras individuais, definição de metas, preparo do portfólio individual, solicitação de auxílios financeiros, manejo do estresse emocional, habilidades de negociação e de resolução de conflitos, estilos de liderança.

Estratégias para atualização de habilidades clínicas, profissionalismo, habilidades de comunicação, medicina baseada em evidências, uso das tecnologias da informação.

Quadro 3. Formatos frequentemente descritos em programas de capacitação e desenvolvimento docente ${ }^{6,10}$.

\begin{tabular}{ll}
\hline Formatos & Características \\
\hline HABITUAIS & $\begin{array}{l}\text { Workshops, palestras interativas, discussões, exercícios em pequeno grupo, } \\
\text { role-playing e simulações, discussões de experiências na ação docente. }\end{array}$
\end{tabular}

\section{ALTERNATIVOS}

Programas longitudinais

Orientação ou tutoria (mentoring)

Tutoria (mentoring) por pares

Aprendizado autodirigido

Instrução assistida por computador

Aprendizagem no trabalho
Parte do tempo do docente é dedicado por um ou dois anos para incrementar suas habilidades em papéis docentes específicos.

Programas de orientação informal ou institucionalizada em que se estabelecem grupos de pares colaborativos, envolvendo em geral a relação docente júnior (mentee) e docente sênior (mentor).

Interação entre pares de docentes em formação, com foco na atuação docente no ensino superior, tendo lugar no local de prática dos participantes, permitindo aprendizado individualizado e promovendo a colaboração.

O próprio docente reflete sobre o seu trabalho na educação e identifica aspectos que precisam ser melhorados, a partir da autoreflexão, da avaliação dos estudantes e do feedback que eventualmente recebem dos pares.

Uso de recursos computacionais para a autoaprendizagem ou para comunicação com pares, recursos online complementares em programas presenciais específicos, discussões em grupo baseadas na web.

Baseia-se na noção da efetividade do aprendizado no ambiente e no contexto do trabalho e funciona a partir da reflexão e comunicação e discussão entre pares que passam a constituir comunidades de pratica. 
nidade de refletir, dentro do processo de formação, sobre a instituição como um todo. Por exemplo, alguns autores sugerem que são aspectos importantes a considerar a cultura institucional, os estilos de liderança prevalentes, bem como a estrutura organizativa e normativa da instituição. ${ }^{5,6}$

- Desenvolvimento profissional acadêmico: em certos programas, considera- se importante, além de prover capacitação para o ensino, também facilitar o desenvolvimento de habilidades acadêmicas profissionais, para melhor enfrentar as responsabilidades inerentes à profissão docente e orientar adequadamente os docentes, na condução da própria carreira profissional. Nestes casos, as atividades incluem tópicos relativos à definição de metas, preparo do portfólio individual, solicitação de auxílios financeiros, manejo do estresse emocional, habilidades de negociação e de resolução de conflitos e diferentes estilos de liderança. Programas que adotam esta estratégia, em geral o fazem considerando a perspectiva individual e não institucional. ${ }^{4,6}$

- Abordagem de outras áreas específicas do ensino: autores como Steinert \& Mann (2006) ${ }^{6}$ referem que, dentro da formação docente continua, às vezes são incluídas áreas que não são ensinadas em outro lugar. Estes autores oferecem como exemplo a atualização de habilidades clínicas, profissionalismo, habilidades de comunicação, medicina baseada em evidências e uso das tecnologias da informação.

Com relação aos formatos e métodos empregados, existe também uma interessante variedade. ${ }^{6}$ Entre os formatos mais populares estão os workshops, as palestras interativas, discussões e exercícios em pequeno grupo, role-playing e simulações, junto com aprendizagem baseada na experiência.

Outros formatos, que podem ser considerados alternativos, são apresentados a seguir.

- Programas longitudinais: os docentes empregam 10 a $20 \%$ de seu tempo durante um ou dois anos para incrementar suas habilidades em papéis docentes específicos. Estes programas também permitem a promoção e o desenvolvimento de liderança educacional e acadêmica, bem como aperfeiçoamento das habilidades de ensino.

- Orientação ou tutoria (mentoring): esta modalidade de desenvolvimento docente tem uma tradição de longa data e tem sido empregada para promover o aperfeiçoamento do pessoal que atua na educação superior. São programas de orientação em que se estabelecem grupos de pares colaborativos, envolvendo em geral a relação docente júnior (mentee) e docente sênior (mentor). Este tipo de relação pode ser informal ou institucionalizada, mas a qualidade da orientação ou tutoria depende da relação de colaboração que se estabelece entre o mentor e o seu orientado. Encontra-se na literatura a descrição de um modelo de orientação, que apresenta três elementos principais: apoio ao orientado, oferecimento de desafios superáveis e provimento de visão antecipada da futura carreira do indivíduo. ${ }^{7}$ São programas de desenvolvimento docente em que o foco é a carreira pessoal do docente e não tem como objetivo principal o aperfeiçoamento das habilidades de ensino.

- Tutoria (mentoring) por pares: embora semelhante à modalidade anterior, este tipo de orientação dela difere em dois aspectos: a relação é entre pares de características semelhantes (docentes em formação) e o foco é a atuação docente no ensino superior, e não a carreira dos participantes. Nesta modalidade, os docentes ajudam-se mutuamente para refletir e melhorar seu ensino. Implica em acordo entre os participantes sobre os objetivos, a possibilidade de observação focalizada das atividades de ensino pelo par e a prática contínua de análise, feedback e apoio. Este formato é particularmente atrativo porque tem lugar no local de prática do participante, permite aprendizado individualizado e promove a colaboração. Este é um formato não tradicional porque o processo de ensino é considerado como uma responsabilidade principal da pessoa mais experiente na área de interesse, sobre quem é depositada a função de guiar e orientar. Nem sempre é reconhecido que os pares também podem ser referencias importantes como foco de interação e fonte de aprendizado.

- Aprendizado autodirigido: depende fundamentalmente da habilidade do próprio docente para refletir, tanto "na ação" como "sobre a ação", e também da sua habilidade para sozinho identificar áreas pessoais que precisam ser melhoradas. Os programas de desenvolvimento docente podem contribuir para o aprendizado autodirigido estimulando os docentes a determinar as suas próprias necessidades (a partir da autoreflexão, da avaliação dos estudantes e do feedback que eventualmente recebem dos pares). Além disso, os programas podem ajudar os docentes a planejar as suas próprias atividades de desenvolvimento. 
- Instrução assistida por computador: existe uma variedade de recursos computacionais que podem funcionar sozinhos, mediante a autoaprendizagem, ou então como complemento de outras atividades. ${ }^{6}$ Baseados na experiência existente, os programas do aprendizado e os recursos online podem ser considerados complementares em programas presenciais específicos de desenvolvimento docente. Podem, também, ser utilizados como parte de uma abordagem em etapas, sendo mais úteis nas etapas mais avançadas da formação de professores. As discussões em grupo baseadas na web podem também ser uteis para aprendizes em todos os níveis e é possível fazer uso delas tanto nos próprios locais das faculdades, como em sítios distantes. Os fatores que fazem deste formato uma boa oportunidade são a decrescente disponibilidade de tempo dos docentes para o seu desenvolvimento profissional, o crescimento explosivo da tecnologia para criar programas interativos e também o desejo de melhorar o acesso para os docentes.

- Aprendizagem no trabalho: é crescente atualmente a compreensão da impossibilidade de se separar o trabalho e a aprendizagem, bem como da pertinência da aprendizagem ocorrer no ambiente e no contexto do trabalho. ${ }^{6,8,9,10}$ Trabalhando juntos e participando de uma comunidade maior, os docentes podem construir novo conhecimento, compreender e desenvolver abordagens dos problemas que enfrentam no ensino e aprendizado. As comunidades de pratica $^{10}$ trabalham em dois níveis. O primeiro nível, o do aprendizado centrado no trabalho, é um tipo de aprendizado baseado nas experiências que ocorrem todos os dias no lugar de trabalho; ali, os docentes podem ser apoiados para ver suas experiências diárias como experiências de aprendizagem e serem estimulados a refletir com colegas e estudantes sobre elas e desenvolver novas perspectivas sobre ensino e aprendizagem. $\mathrm{O}$ segundo nível, o da comunidade de pratica, é um nível do desenvolvimento docente propriamente dito, porque se constitui uma rede de pessoas com uma base comum de conhecimentos, de crenças, valores e experiências focalizadas em um objetivo comum: neste caso, o aperfeiçoamento do ensino e da aprendizagem. Fazer parte de uma comunidade de prática permite que se atinja nova compreensão, com a aquisição de novos conhecimentos e o desenvolvimento de perspectivas diversas sobre os problemas e desafios que se apresentam ao docente no seu cotidiano. ${ }^{11}$
Além dos conteúdos e formatos, um aspecto importante do desenvolvimento docente é a motivação dos docentes para mudar suas concepções e práticas e dedicar tempo e esforço para realizar um verdadeiro processo de formação em educação. Uma perspectiva necessária para poder abordar a motivação dos docentes é aquela que inclui tanto um enfoque individual como organizacional e que considera a formação como um processo continuo. Do ponto de vista individual, é preciso que a proposta de formação esteja centrada na aprendizagem, baseada na melhor evidencia disponível sobre práticas pedagógicas, e que seja também avaliada quanto a sua efetividade. Do ponto de vista organizacional é fundamental pensar a instituição como promotora do desenvolvimento docente, por meio de estímulos concretos para a melhora pedagógica e para a criação de um meio ambiente favorável à formação continua. São importantes neste sentido as instancias de apoio para os docentes que tenham iniciativas de inovação didática, a existência de mecanismos de recompensas para estas iniciativas e para a criatividade e a inovação, feita por meio dos processos de promoção e permanência e da estrutura salarial, entre outros. No contexto de uma organização deste tipo, a formação e desenvolvimento docente podem existir de uma forma que combine diferentes formatos, de acordo as necessidades dos vários docentes.

\section{Avaliação de programas de capaci- tação e desenvolvimento docente}

A avaliação dos programas de capacitação e desenvolvimento docente é uma atividade essencial para a o seu aperfeiçoamento. Entende-se aqui como avaliação a obtenção de informações e a sua subsequente análise e interpretação dos resultados obtidos no sentido de ter elementos concretos que subsidiem a tomada de decisões. No contexto de uma instituição que iniciou ou que mantém programas de capacitação e desenvolvimento docente, as decisões mais importantes são, em geral, sobre o que se deve mudar para que os objetivos sejam atingidos com mais propriedade, ou para que haja aumento notável da qualidade do que foi feito. Além disso, o exercício da avaliação, por si mesmo, preenche outras funções que, no campo educacional são da maior importância, como assegurar aos participantes que foram eles capazes de adquirir as habilidades e competências esperadas, bem como mostrar aos facilitadores que eles cumpriram bem o seu papel. 
A avaliação de programas educacionais é um tema complexo, que apresenta muitas facetas e implicações ${ }^{12,13,14}$, podendo ser entendida e desenvolvida segundo diferentes modelos. Não cabe aqui, portanto, uma discussão aprofundada do tema, mas somente a apresentação de algumas noções básicas, que se pretende tenha caráter mais prático.

Neste sentido, é importante considerar dois aspectos: o "que" avaliar, ou seja, quais os elementos do programa constituirão o foco da avaliação, e o "como" avaliar, ou seja, quais os métodos e instrumentos serão empregados na avaliação. Um referencial interessante para auxiliar as tomadas de decisões sobre estes elementos é o chamado "modelo de Kirkpatrick". ${ }^{13}$ Este modelo contempla quatro diferentes níveis de abrangência, que servem de orientação sobre os focos da avaliação e, que por sua vez, remetem a tipos de dados que devem ser colhidos com os instrumentos mais adequados para isto, conforme consta do Quadro 4.

As reações dos participantes dos programas de capacitação e desenvolvimento docente, entendidas como suas impressões e opiniões sobre o que vivenciou, bem como o seu grau de satisfação em ter participado, podem ser avaliadas por instrumentos diversos, como questionários, entrevistas e discussões em grupos.

O que foi aprendido pelos participantes, em termos da aquisição de novos conhecimentos e da incorporação de habilidades e competências mais especí- ficas para a atuação no ensino podem ser avaliadas por instrumentos variados, que incluem desde a autoavaliação, que é empregada com frequência, até exames de conhecimentos ou de habilidades, que são menos frequentemente utilizados. Mais comum e, possivelmente, mais efetiva, como demonstração dos resultados dos programas, é a avaliação das mudanças de comportamentos dos participantes, como resultado direto da aquisição de conhecimentos e da incorporação de habilidades e competências. Este tipo de avaliação é habitualmente feito também por autoavaliação, mas pode ser realizada mediante a observação do desempenho do participante em atividades de ensino e aprendizado, feita por pares ou por outros docentes mais experientes, atuando como observadores externos. Por fim, o impacto positivo dos programas de capacitação e desenvolvimento docente sobre o aprendizado dos estudantes, que constitui a sua meta final e mais importante, pode ser demonstrado pelos ganhos na aquisição de conhecimentos e na incorporação de novas habilidades pelos estudantes cujo aprendizado foi facilitado pelos participantes do programa, o que é feito com os métodos habituais de avaliação de competências do estudante.

O "modelo de Kirkpatrick"13 é bastante interessante para o entendimento da abrangência que podem ter os programas de capacitação e desenvolvimento docente, mas dificilmente a avaliação dos programas, nas condições do mundo real, ultrapassa o primeiro estágio, de avaliação das reações dos participantes.

\section{Quadro 4. Elementos fundamentais na avaliação de programas de capacitação e desenvolvimento docente, com base no "modelo de Kirpatrick". ${ }^{13}$}

$\begin{array}{ll}\text { O “Que” Avaliar } & \text { "Como” Avaliar } \\ \begin{array}{l}\text { REAÇÕES } \\ \text { (Impressões, grau de satisfação em ter participado) }\end{array} & \text { Questionários, Entrevistas, Grupos Focais }\end{array}$

APRENDIZADO

(aquisição de conhecimento, habilidades e

competências)

MUDANÇAS DE COMPORTAMENTOS
Auto-avaliação, Avaliação por pares Observação da prática por observador externo 


\section{Experiências na condução de programas de capacitação e desenvolvimento docente}

A literatura especializada registra incontáveis experiências de programas de capacitação e desenvolvimento docente. Esta diversidade é provavelmente justificada pela necessidade de os programas atenderem a especificidades institucionais, que são diversificadas e também variáveis ao longo do tempo.

Neste segmento, serão descritas experiências de duas instituições sul-americanas distintas, a Facultad de Ciencias Médicas da Universidad Nacional de Cuyo, em Mendoza, Argentina (FCMUNCuyo), e da Faculdade de Medicina de Ribeirão Preto da Universidade de São Paulo (FMRP-USP).

Desde a década de 1980 a FCM-UNCuyo desenvolve atividades de formação para seus docentes de graduação e que têm evoluído acompanhando as necessidades institucionais e curriculares, bem como as demandas de grupos de docentes. Desde 2010, a FCM-UNCuyo tem trabalhado para compor elenco renovado e estável de disciplinas que sejam de interesse para todos os docentes. Isto tem sido feito atualizando os conteúdos de cada uma delas e incorporando disciplinas sobre tópicos novos. A Tabela 1 mostra as principais características do elenco atual de disciplinas de capacitação e desenvolvimento docente da FCM-UNCuyo.

Este elenco de disciplinas é oferecido, em sequência, em todos os anos e está disponível para todos os docentes da Faculdade. Seu objetivo principal é que os professores possam tomar distância das suas próprias concepções e dos seus hábitos pedagógicos para poder analisá-los à luz de outras perspectivas conceituais distintas. Todas as disciplinas oferecem elementos teóricos sobre cada tópico e atividades práticas de análise das rotinas didáticas, assim como de elaboração de novas propostas para o seu aperfeiçoamento.

Com relação aos temas de cada disciplina, a de "Estratégias didáticas em saúde" aborda especificamente o planejamento didático, o trabalho didático com palestras, o trabalho em grupos pequenos de estudantes, a aprendizagem baseada em problemas, a aprendizagem baseada em tarefas e o emprego desimulações no ensino. A disciplina de "Avaliação da aprendizagem", por sua vez, privilegia os critérios de qualidade das avaliações e a seleção dos instrumentos mais adequados, o que é feito por meio de atividades teóricas e práticas. No caso da disciplina "O Currículo", o conteúdo é de natureza mais teórica, que permite ao docente participante familiarizar-se com diversos enfoques conceituais sobre este construto, bem como conhecer os aspectos principais das estruturas curriculares da FCM-UNCuyo. Já as disciplinas "Tutoria em ABP" e "Papel como tutor do docente universitário" dedicam-se a duas funções especiais dos professores. A primeira função é a do papel do docente em uma estratégia especificamente centrada no aluno, enquanto que a segunda função refere-se ao papel do docente frente às diferenças individuais dos estudantes nos processos e nos resultados da sua aprendizagem.

É interessante mencionar que na Argentina, a Comissão Nacional de Avaliação e Acreditação Universitária de Argentina exige que, em todas as faculdades do país, os professores exerçam ao menos 50 horas anuais em cursos de formação pedagógica. Os docentes da FCM-UNCuyo podem escolher qualquer combinação de cursos da lista mencionada para cumprir com essa obrigação. Ao nível central da Universidade existe um curso específico de "Especialização em Pedagogia Universitária", desde a década de 1990. A partir de 2007, passou a existir um Programa de Mestrado na mesma temática. Desde 2010, até 2013, $35 \%$ dos professores cursaram entre uma e quatro disciplinas do programa de FCM-UNCuyo (Tabela 1) e 9\% deles concluíram o mencionado curso de especialização.

O principal ganho havido com o programa de disciplinas oferecido pela FCM-UNCuyo tem sido as mudanças e inovações geradas em algumas das disciplinas de graduação em que os docentes participantes atuam. Essas mudanças relacionam-se à programação da disciplina, atualização de metodologias e técnicas didáticas e seleção e aplicação de instrumentos mais confiáveis de avaliação da aprendizagem do estudante. Não obstante, os progressos têm sido aquém do esperado porque, muitas vezes os docentes participantes das disciplinas do programa não têm a responsabilidade principal de decisão nas áreas e disciplinas. Outro motivo provável é que não existe um incentivo específico para quem decide realizar um aperfeiçoamento pedagógico na disciplina em que atua, nem uma sanção para quem não o realiza. Isto torna difícil motivar os docentes que ainda não participaram do programa, ou os que participaram e poderiam ter intenção de inovar em suas áreas, e convencê-los do valor de iniciar este processo. Este é hoje o principal desafio de FCM-UNCuyo nas suas atividades de capacitação e desenvolvimento docente. 
Tabela 1. Características atuais das disciplinas de capacitação e desenvolvimento docente oferecidas regularmente desde 2010 pela FCM- UNCuyo (Mendoza, Argentina) a seus docentes.

\begin{tabular}{|c|c|c|}
\hline \multicolumn{3}{|c|}{ Características das disciplinas } \\
\hline Título & $\begin{array}{l}\text { Carga horária } \\
\text { (horas) }\end{array}$ & Formato \\
\hline Estratégias didáticas em saúde & 30 & \\
\hline Avaliação da aprendizagem & 40 & Palestras interatıvas e atıvıdades em \\
\hline O Currículo & 20 & campus virtual. \\
\hline $\begin{array}{l}\text { Tutoria em aprendizagem baseada em } \\
\text { problemas (ABP) }\end{array}$ & 10 & $\begin{array}{l}\text { Palestras interativas e atividades de observação, } \\
\text { análise e planejamento de tutoria em ABP. }\end{array}$ \\
\hline Papel como tutor do docente universitário & 10 & $\begin{array}{l}\text { Palestras interativas com atividades de reflexão } \\
\text { sobre a própria prática docente. }\end{array}$ \\
\hline
\end{tabular}

Na FMRP-USP não existe um programa formal de capacitação de docentes ingressantes, visto que as admissões são exclusivas para egressos dos programas de pós-graduação estrito senso. É porém no nível dos programas de mestrado e de doutorado que se dá a capacitação docente, principalmente em disciplinas formais da pós-graduação nos vários programas da instituição. A capacitação é completada com a participação efetiva do pós-graduando em atividades formais dos cursos de graduação da unidade, que se dá no âmbito de um programa formal específico da Universidade, o "Programa de Apoio ao Ensino" (PAE). No programa de Clínica Médica, como consequência da aprovação recente de um grande projeto de fomento ao ensino e a pesquisa científica na área da Educação nas Profissões da Saúde (Edital CAPES 024/2010 - Pró-Ensino na Saúde) foram criadas duas disciplinas, articuladas, entre si, que funcionam como módulos complementares para a capacitação docente. Os tópicos que constituem estas disciplinas (Quadro 5) são desenvolvidos pelos pós-graduandos participantes mediante o emprego de técnicas didáticas variadas, o que também permitem que experimentem, na prática, a utilização destes métodos de "ensinagem". ${ }^{15}$

Os programas de desenvolvimento docente na FMRP-USP têm sido caracteristicamente episódicos e para atendimento de demandas específicas. Estas demandas são ligadas muito frequentemente à introdução de novos métodos de ensino ou de avaliação. Exemplos de experiências recentes são a exposição de docentes dos cursos de Fisioterapia, Terapia Ocupacional e Fonoaudiologia a experiências bem sucedidas no curso de Medicina: métodos estruturados de avaliação de habilidades clínicas e ao teste de progresso. Isto foi feito por meio de oficina com dois dias de duração, conduzida por docentes do curso de Medicina. Outro exemplo foi o treinamento de professores para prover educação tutorial para ensino na comunidade empregando a estratégia da "problematização", conduzida também por oficina de um dia de duração, coordenada por docentes de outra universidade. A introdução na estrutura curricular do curso de Medicina de disciplina que visa introduzir os estudantes de início de curso à princípios e técnicas de comunicação com pacientes, proposta para ser desenvolvida com métodos inovadores, como "protagonização" (role-playing) e discussão de vídeos, também demandou a organização de oficina de um dia para os professores que iriam atuar nesta disciplina. Esta oficina foi conduzida por docentes da FMRP-USP que já utilizavam esta técnica, em menor escala. Outro exemplo mais recente foi o da difusão, entre maior número de professores, de técnicas de ensino de habilidades clínicas com o emprego de simuladores, motivada pela aquisição de modernos manequins e 
Quadro 5. Conteúdo programático das disciplinas de "Tópicos em educação superior nas profissões da saúde" oferecidas a pós-graduandos da Faculdade de Medicina de Ribeirão Preto, Universidade de São Paulo.

\begin{tabular}{|c|c|}
\hline Módulo básico & Módulo avançado \\
\hline $\begin{array}{l}\text { - Teorias de aprendizagem, aprendizado de adultos e } \\
\text { ambiente educacional }\end{array}$ & $\begin{array}{l}\text { - Ensino clínico em cenários tradicionais - enfermarias } \\
\text { e ambulatórios }\end{array}$ \\
\hline - Técnicas de "ensinagem" & - Emprego de simulações no ensino e na avaliação \\
\hline - Diferentes concepções e formatos de currículos & - Educação à distância e aprendizado eletrônico \\
\hline - Planejamento e gestão educacional & $\begin{array}{l}\text { - Novos cenários de aprendizagem - Ensino na comuni- } \\
\text { dade }\end{array}$ \\
\hline $\begin{array}{l}\text { - Estratégias inovadoras para métodos de ensino } \\
\text { tradicionais }\end{array}$ & $\begin{array}{l}\text { - Desenvolvimento psicossocial do adolescente e do } \\
\text { adulto jovem - Apoio ao estudante }\end{array}$ \\
\hline $\begin{array}{l}\text { - Aprendizado baseado em problemas e problematiza- } \\
\text { ção }\end{array}$ & $\begin{array}{l}\text { - Capacitação para a docência e desenvolvimento } \\
\text { docente }\end{array}$ \\
\hline $\begin{array}{l}\text { - Avaliação somativa e formativa do estudante } \\
\text { - Avaliação de cursos e programas }\end{array}$ & $\begin{array}{l}\text { - Mérito acadêmico (scholarship) em atividades educa- } \\
\text { cionais, profissionalização e carreira docente }\end{array}$ \\
\hline
\end{tabular}

conduzida por um grupo de professores que já tinham experiência com estas técnicas. Estas experiências têm sido consideradas, na sua maioria, bem sucedidas, uma vez que resultaram em alta satisfação dos participantes e na introdução efetiva das técnicas propostas, mas não se dispõe de dados objetivos sobre seu impacto no aprendizado dos estudantes de graduação.

\section{Dificuldades e Desafios}

A formação de professores para o ensino superior na área das profissões da saúde e a subsequente manutenção e aperfeiçoamento da competência educacional adquirida enfrenta habitualmente inúmeras dificuldades e precisa superar diversos desafios (Quadro 6). A primeira dificuldade é de natureza cultural. Em muitas instituições, prevalece ainda a noção de que, para ser um bom professor, basta conhecer bem e a fundo o que se deve ensinar, caracterizando, deste modo, o conceito da função exclusiva do professor como transmissor do conhecimento e a ignorância ou negligência em relação à grande diversidade de papéis que este deve desempenhar. Este conceito "reducionista" é, frequentemente, compartilhado pelas instituições e pelos próprios docentes, que não se veem como professores, mas apenas como profissionais que, circunstancialmente, atuam no ensino e na formação de outros profissionais. Na Medicina, por exemplo, não é incomum encontrar-se docentes de áreas clínicas que se veem somente como médicos e se dedicam ao aperfeiçoamento da sua competência clínica, mas não se veem como professores e, portanto, não se preocupam em melhor se capacitar para a prática do ensino. Do mesmo modo, docentes das áreas das ciências biomédicas básicas se veem mais como investigadores científicos e se preocupam, predominantemente, com o domínio cognitivo dos temas do campo em que atuam e com o aumento da sua proficiência e produção em pesquisa. Trata-se, então, de uma questão de identidade profissional, que pode constituir um obstáculo à capacitação e ao desenvolvimento docente na área educacional.

Em outras instituições, em geral maiores e com maior grau de diversificação das suas atividades acadêmicas, a barreira ao fomento de programas de capacitação para a docência e de desenvolvimento profissional neste campo é mais de natureza ideológica. Esta se caracteriza pela existência da noção de que estes programas são necessários, sobretudo para aperfeiçoar o ensino no nível dos cursos de graduação, mas existe também a opção deliberada de que os investimentos e os mecanismos de recompensa sejam direcionados a outras atividades, como, por exemplo, a investigação científica. 
Quadro 6. Dificuldades e desafios para os programas de capacitação e desenvolvimento docente.

\begin{tabular}{ll} 
Dificuldades & Desafios \\
\hline $\begin{array}{l}\text { Culturais } \\
\text { - Desconsideração dos inúmeros papéis docentes }\end{array}$ & - Superar as barreiras culturais e ideológicas \\
- Falta de identidade profissional docente & - Minimizar as dificuldades institucionais \\
- Individualismo & - Conseguir recursos \\
- Resistência às mudanças & - Formar lideranças na área educacional \\
Institucionais & - Demonstrar os benefícios dos programas \\
- Desvalorização das atividades de ensino & \\
- Reduzida participação dos sistemas de saúde & \\
Materiais & \\
- Falta de orçamento específico & \\
Operacionais &
\end{tabular}

No plano institucional, estas barreiras à capacitação e ao desenvolvimento docente no campo educacional, de natureza predominantemente cultural ou ideológica, geram outras, ainda mais poderosas, que dizem respeito às políticas e práticas de recrutamento, seleção e admissão de docentes, bem como de reconhecimento e valorização do seu trabalho na carreira docente. Se a capacitação educacional para a docência não é considerada para a admissão e, no caso dos professores já contratados, se as evidencias de investimento pessoal no desenvolvimento docente não são levadas em conta para a valorização do trabalho ou para a promoção na carreira, os profissionais vão se sentir, naturalmente, pouco estimulados a se engajar nestas atividades. Sob a perspectiva dos programas de capacitação e desenvolvimento docente, estes fatores contribuem para a instauração de umverdadeiro "currículo oculto", que exerce poderosa influência negativa sobre os professores, em relação ao desenvolvimento docente de caráter educacional ${ }^{16}$

Nilce Costa, da Universidade Federal de Goiás, em um interessante trabalho de revisão que procura identificar fatores que dificultam as mudanças na prática docente em Medicina ${ }^{17}$, que levem à sua evolução, com a implementação de novos paradigmas de ensino, ressalta a importância de alguns fatores que dizem respeito tanto às instituições como aos docentes, individualmente. Entre estes, ela cita a desvalorização das atividades de ensino pelas próprias instituições, a falta de identidade profissional docente, a própria deficiência na capacitação docente ou de for- mação pedagógica do professor de Medicina, a resistência docente a mudanças e o individualismo dos professores universitários. Este conjunto de fatores pode, também, trazer dificuldades à introdução de programas de desenvolvimento docente e ao engajamento neles dos professores.

Os fatores de natureza cultural ou ideológica presentes nas instituições e envolvendo os seus dirigentes e membros do corpo docente contribuem para que recursos financeiros, quando existentes, não sejam priorizados para a finalidade de manter programas de capacitação docente no campo educacional.

Junta-se a isto, um outro obstáculo à capacitação e ao desenvolvimento docente no campo educacional, que é a relativa carência de recursos humanos preparados para liderar programas específicos com esta finalidade $^{18}$, especialmente nas instituições voltadas ao ensino das profissões da saúde. Isto porque, as melhores condições de liderança e de condução das atividades próprias destes programas seriam atingidas pela atuação conjunta de docentes da área das ciências da Educação e por professores das próprias profissões da Saúde. Estes últimos, porém, deveriam ter competências bem desenvolvidas na área educacional, além da experiência nas áreas específicas das profissões da saúde em que atuam, que lhe trouxesse familiaridade com as preocupações dos docentes e com as circunstâncias e condições de trabalho dos eventuais professores engajados os programas.

No plano institucional, mesmo quando os dirigentes e professores tem a noção da importância do 
oferecimento de atividades regulares de capacitação e desenvolvimento docente no campo educacional, pode haver a dificuldade da sua institucionalização, ou seja, de tornar os programas existentes em atividades permanentes, como parte da vida funcional dos professores, especialmente para aqueles que tem atividades clínicas. ${ }^{9}$ Para estes professores de áreas clínicas, ou para profissionais não docentes que exerçam funções de ensino ou supervisão de estudantes ou estagiários, a probabilidade de institucionalização bem sucedida de programas regulares de capacitação e desenvolvimento docente aumenta se houver envolvimento definido dos sistemas de saúde, em parceria com as instituições educacionais. ${ }^{19}$

Por outro lado, muitas das instituições que conseguiram superar as barreiras antes apresentadas e que apresentam programas regulares de capacitação e desenvolvimento docente no campo educacional, podem enfrentar um tipo particular de desafio, que é o de sair do plano meramente do ensino ou do aperfeiçoamento das técnicas didáticas para as atividades mais abrangentes de preparo para atuação em outros papéis, como os antes apresentados ${ }^{9}$, ou, ainda, para fazer que o docente tenha uma visão mais abrangente dos processos educacionais.

Por fim, um desafio a ser enfrentado por todos os que militam no campo da capacitação e do desenvolvimento docente é a própria avaliação da efetividade dos programas, no sentido de demonstrar que a introdução e a condução deste tipo de atividade realmente trazem benefícios concretos, na forma da modificação dos comportamentos dos professores e do aperfeiçoamento das suas práticas de ensino e, com isto, realmente de contribuir para o aperfeiçoamento da formação geral e profissional dos estudantes. ${ }^{9}$

\section{Principais pontos de interesse}

- Os docentes que atuam no ensino superior na área da saúde, além da expertise na sua disciplina, devem ter também preparo na área educacional, obtido em programas específicos de capacitação e desenvolvimento docente;

- A necessidade de preparo específico para a atuação no ensino decorre da grande variedade de papéis que o professor deve desempenhar, incluindo os de facilitador do aprendizado dos estudantes, planejador de cursos, orientador de indivíduos ou grupos, produtor de material didático, avaliador do aprendizado e modelo de comportamento profissional;
- Os programas de capacitação e desenvolvimento docente podem ser muito diversificados quanto ao conteúdo e a forma, mas em geral cobrem temas educacionais e institucionais, bem como aspectos do planejamento e gerenciamento das carreiras acadêmicas; podem ter formato mais convencional (aulas e oficinas) ou de programas longitudinais prolongados ou de orientação por pares ou docentes mais experientes;

- A avaliação dos programas de capacitação e desenvolvimento docente é uma atividade essencial para a o seu aperfeiçoamento, devendo focalizar não só as reações e impressões dos participantes, mas também o que adquiriram de novas habilidades. Idealmente, deve também contemplar eventuais mudanças no seu comportamento profissional e o impacto no aprendizado dos estudantes;

- A capacitação e o desenvolvimento docente no campo educacional enfrentam inúmeras dificuldades e desafios, que incluem as de ordem cultural e ideológica, as questões da identidade profissional do docente, $\mathrm{o}$ individualismo e a resistência às mudanças, bem como a carência de recursos materiais e humanos para a sua efetiva execução.

\section{Referências bibliográficas}

1. Wright S, Wong A, Newill C. The impact of role models on medical students training. J Gen Intern Med. 1997;12: 53-6.

2. Harden RM, Crosby J. AMEE Education Guide No. 20: The good teacher is more than a lecturer: the twelve roles of the teacher. Med Teach. 2000; 22: 334-47.

3. Paice E, Heard S, Moss F. How important are role models in making good doctors? BMJ. 2002; 325: 707-10.

4. Daley SP, Broyles SL, Rivera LM, Brennan JJ, Lu ER, Reznik V. A conceptual model for faculty development in academic medicine: the underrepresented minority faculty experience. $J$ Natl Med Assoc. 2011; 103: 816-21.

5. Hueppchen N, Dalrymple JL, Hammoud MM, Abbott JF, Casey PM, Chuang AW, Espey EL. To the point: medical education reviews-ongoing call for faculty development. Am J Obstet Gynecol.2011; 205, 171-6.

6. Steinert Y, Mann KV. Faculty development: principles and practices. J Vet Med Educ 2006; 33: 317-24.

7. Daloz L. Effective teaching and mentoring: Realizing the transformational power of adult learning experience. San Francisco: Josey-Bass, 1986.

8. Davis DA, Prescott J, Fordis Jr CM, Greenberg SB, Dewey CM, Brigham T, Tenner Jr TE. Rethinking CME: an imperative for academic medicine and faculty development. Acad Med. 2011; 86: 468-73.

9. McLeod PJ, Steinert Y. The evolution of faculty development in Canada since the 1980s: Coming of age or time for a change? Med Teach 2010; 32: 31-5. 
10. Steinert Y. Faculty development: From workshops to communities of practice. Med Teach 2010; 32: 425-8.

11. Lave J, Wenger E. Situaded learning: legitimate periphera participation. Cambridge University Press, 1991.

12. Wilkes M, Bligh J. Evaluating educational interventions. BMJ. 1999; 318:1269-72.

13. Morisson J. ABC of Learning and Teaching in Medicine: Evaluation. BMJ. 2003: 326: 385-7.

14. Bollela VR, Castro M. Avaliação de programas educacionais nas profissões da saúde: conceitos básicos. Medicina (Ribeirão Preto) 2014;47:332-42.

15. Alves LP, Anastasiou LGC. Estratégias de ensinagem. IN: "Processos de ensinagem na universidade: pressupostos para as estratégias de trabalho em aula". Léa das Graças Camargos Anastasiou (Org.), Ed. Joinville, SC, Capítulo 3, 2007.
16. Hafler JP, Ownby AR, Thompson BM, Fasser CE, Grigsby K, Haidet $P$, et al. Decoding the learning environment of medical education: a hidden curriculum perspective for faculty development. Acad Med. 2011; 86: 440-4.

17. Costa NMSC. Docência no Ensino Médico: por que é tão difícil mudar? Rev Bras Educ Med. 2007; 31: 21-30.

18. Tekian A, Roberts T, Batty HP, Cook DA, Norcini J. Preparing leaders in health professions education. Med Teach. 2014; 36: 269-71.

19. Foster K, Laurent R. How we make good doctors into good teachers: A short course to support busy clinicians to improve their teaching skills. Med Teach. 2013; 35: 4-7. 